\title{
Multi-objective NSGA-II based shape optimisation of the cross-sectional shape of passively cooled heat sinks
}

\begin{tabular}{|r|l|}
\hline Journal: & International Journal of Numerical Methods for Heat and Fluid Flow \\
\hline Manuscript ID & HFF-10-2020-0656.R1 \\
\hline Manuscript Type: & Research Article \\
\hline Keywords: & $\begin{array}{l}\text { Heat sink design, Genetic algorithm, Shape optimisation, Natural } \\
\text { convection, CFD }\end{array}$ \\
\hline \multicolumn{2}{|l}{} \\
\hline
\end{tabular}

\section{SCHOLARONE" \\ Manuscripts}




\section{Multi-objective NSGA-II based shape optimisation of the cross-sectional shape of passively cooled heat sinks}

\section{Structured Abstract:}

Purpose:

The purpose of the study is to optimise the cross-sectional shape of passively cooled horizontally mounted pin fin heat sink for higher cooling performance and lower material usage.

Design/Methodology/Approach:

Multi-objective shape optimisation technique is used to design the heat sink fins. Nondominated sorting genetic-algorithm (NSGA-II) is combined with a geometric module to develop the shape optimiser. High fidelity Computational Fluid Dynamics (CFD) is used to evaluate the design objectives. Separate optimisations are carried out to design the shape of bottom row fins and middle row fins of a pin-fin heat sink. Finally, a computational validation was conducted by generating a 3D pin-fin heat sink using optimised fin cross-sections and comparing its performance against the circular pin-fin heat sink with the same inter-fin spacing value.

Findings:

Heat sink with optimised fin cross sections, has $1.6 \%$ higher cooling effectiveness than circular pin-fin heat sink of same material volume, and has $10.3 \%$ higher cooling effectiveness than the pin-fin heat sink of same characteristics fin dimension. The special geometric features of optimised fins which resulted in superior performance are highlighted. Further, Pareto optimal fronts for this multi-objective optimisation problem are obtained for different fin design scenarios.

Originality/Value:

For the first time, passively cooled heat sink's cross sectional shapes are optimised for different spatial arrangements, using NSGA-II based shape optimiser, which makes use of CFD 
solver to evaluate the design objectives. The optimised, high performance shapes will find direct application to cool power electronic equipment.

Keywords: Heat sink design, Genetic algorithm, Shape optimisation, Natural convection, CFD

\section{Introduction}

Thermal management is a key challenge in modern microelectronics system design due to ever increasing levels of miniaturisation, integration, and operating frequency. Thermal management challenges are clearly also encountered in a wide range of engineering problems. Forced convective cooling is used in situations where the performance of natural convective cooling does not meet specified design requirements. However, this comes at an additional energy cost so enhancement of the performance of natural convective cooling systems may enable their use where forced convective systems are currently required.

Typically, circular, rectangular or square cross-sectional shaped heat sinks are used in the electronics industry. Such designs evolved based on the knowledge of heat transfer and ease of manufacturing such shapes. Design methodologies have improved markedly in recent years, with a number of differing forms of optimization algorithm able to define heat exchange structures with higher performance than can be achieved using simplistic / parametric optimisation approaches. Designers employ parametric optimisation approach to determine the optimum value of design parameters like number of plate-fins, spacing between the fins, their height etc. during heat sink design. Researchers also use topology optimisation and shape optimisation methods to design heat exchanging structures. In topology optimisation (TO), from the specified design domain, a shape is evolved from an initial material distribution in response to a shape sensitivity value. An alternative to this approach is shape optimisation, wherein only selected design variables are optimised to achieve extremum objective values. Though TO gives more design freedom it suffers from disadvantages such as grey cells (diffused shape boundary). Since TO uses a gradient based optimiser, different material initialisations have to be tested to avoid ending up in local optima. However, shape optimisation with stochastic optimisers can predict global optima. Genetic algorithms (GA) are a popular form of stochastic optimisation. 
Genetic algorithms were inspired by Darwinian natural selection and genetics (Goldberg, 1989). GA based shape optimisers will have either an empirical model or computational fluid dynamics based model to evaluate the objectives corresponding to a design. In 2002, Deb et.al, proposed a fast and elitist multi-objective genetic algorithm known as Non-dominated Sorting Genetic Algorithm (NSGA-II). This algorithm makes use of non-dominated ranking to preserve the important parent population to produce offspring in the later generations.

One of the earliest studies on GA based optimisation of a heat transfer application was by Tayal et.al (1999), wherein they calculated the minimum heat exchange area required for the given heat exchanger requirements. They also compared the performance of GA optimiser against Simulated Annealing, another probabilistic optimiser. Hilbert et.al (2006), performed a multi objective optimisation of a heat exchanging blade shape design considering minimization of pressure drop and maximization of temperature change as objectives for a forced convective study. The study obtained a Pareto front of optimised designs and investigated the ways to decrease computational cost. Subsequently, Peng and Ling (2008) applied a combined neural network (NN) / GA approach to optimise the design of plate fin heat exchangers. The objectives of this study were to minimise weight and the total annual cost, while the design variables are different geometric parameters of plat fin heat sink. The study concluded that GA combined with NN is effective and efficient.

Sanaye and Hajabdollahi (2010) optimised fin pitch, fin height, cold stream flow length and further parameters of plate fin heat exchanger using the NSGA-II algorithm. Maximum effectiveness of heat exchanger (a function of overall heat transfer coefficient) and minimum total pressure drop were considered as objectives and they are calculated using 'number of transfer unit' method. Results of optimisation as Pareto optimal fronts are obtained. They also evaluated the correlation between objective functions and design variables using NN. Hajabdollahi et.al (2011). later extended this work with high fidelity CFD.

Najafi et.al (2011) optimized air-cooled plate fin heat exchanger using multi-objective GA. The total rate of heat transfer and annual cost were considered as objectives while fin height, fin frequency and number of fin layers were considered as design variables. In addition to optimisation, Najafi et.al also evaluated the sensitivity of objective function against different design variables. Ranut et.al (2014) performed a shape optimisation study of a tube bundle, 
as an extension of Hilbert's 2006 work. In this study, both the flow over the shell and flow inside the tube were considered. The results obtained reiterate the importance of taking the internal flow field into account.

Notable work on natural convection on plate fin arrays include that of Bar-Cohen, et.al (2003), who extended the least-material optimisation method to design, multiple vertical rectangular plate fin arrays. The study showed that 'least material approach' is a suitable optimisation design heuristic for plate fin designs. Later, Bahadur and Bar-Cohen (2005) designed a polymer-based pin-fin heat sink for natural convection cooling applications. They studied heat dissipation against different geometric variables including pin-fin height, pin diameter, horizontal spacing, and pin fin density. Finally, the performance of polymer heat sink was compared against conventional aluminum heat sinks.

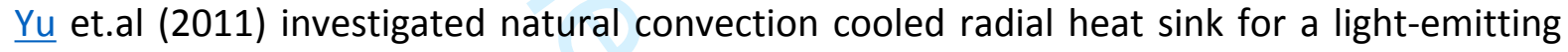
diode (LED) device by a combination of response surface methodology and evolutionary algorithm based optimisation. Different parametric designs, (long fins, long and middle fins and long, middle and short fins) were investigated using CFD and found that long and middle fins gave better performance compared to others. Results were validated through experiments.

Jang et. al (2012) optimized radial pin fin heat sinks for LED applications. The number of fins and length of fins were considered as variables. Different heat flux values are considered. Thermal resistance and mass are considered as objectives. Same authors in their later paper (2014) optimized fin height profile of LED heat sink considering natural convection and radiation heat transfer. The height of the outermost fin and the difference between fin heights and number of fin arrays were adapted. Results showed that taller fins on the outer side provided better cooling performance than taller fins on the inner side.

Joo and Kim (2015) used two objective functions to compare the plate fin and pin fin heat sink performance under natural convection. For pin fin heat sink optmisation correlations are developed using their own experimental study results. The study found that for total heat dissipation objective, plate fins are doing better, but for heat dissipation per unit mass objective pin fin heat sinks are performing better. Recently, Imran et.al (2017) applied multiobjective optimisation based on GA to design water-water chevron type plate heat 
exchangers and also evaluated the sensitivity of objective function with respect to design variables. Other genetic algorithm-based design of heat exchanging fin shapes include Copiello and Fabbri (2009) and Azarkish et al. (2010). An exhaustive review of design optimisation for heat exchangers using various advanced techniques is provided by Venkata Rao et al. (2019).

Apart from shape optimisation, topology optimisation(TO) was also employed to identify the optimum heat sink shape for natural convection conditions. Topology optimisation is a super set of shape optimisation, wherein given the design domain and constraints, the shape evolves during the optimisation. Alexanderson et al. (2016) designed natural convection cooled heat sinks using Density based TO. Later same authors (2018) designed LED heat sinks using TO and compared the performance of TO heat sinks against pin-fin heat sinks. Dede et al. (2015) designed air cooled heat sinks using density based TO considering heat conduction and side surface convection. The authors manufactured the design using additive manufacturing and experimentally validated their performance. Design of forced convection cooled heat sinks using density and level-set TO method and their validation against conventional pin fin heat sinks was conducted by Santhanakrishnan et.al (2018). Later the same authors (2019) designed liquid impingement cooled copper and composite material heat sinks using TO. A review of optimal heat transfer system design using TO is given by Dbouk (2017).

Though NSGA-II based shape optimisers were applied to design heat sinks under natural convection conditions, so far, no work has been done to design the cross-sectional shape of horizontally mounted pin fin heat sinks. Such heat sinks are quite popular in LED cooling and in other electronic appliances. The 2D cross-sectional design is valid at the top-central portion of pin-fin heat sinks. Hence, this study employs shape optimisation techniques to design cross sectional shape of passively cooled pin-fin heat sink fins for different inter-fin spacing values. In this article, section 2 describes about genetic algorithm for multi-objective shape optimisation and section 3 describes about the heat sink design problem and the solution techniques. Section 4 contains results and discussion. Conclusions are given in Section 5. 


\section{Genetic algorithm for multi-objective shape optimisation}

\subsection{Non-dominated Sorting Genetic Algorithm (NSGA-II):}

NSGA-II is an evolutionary multi-objective optimisation algorithm proposed by Deb et al. In this algorithm, initially a population of design variables are taken at random, and their fitness values (objective functions) are evaluated. Based on the fitness values and domination principle, the population is ranked. A solution ' $x 1^{\prime}$ is said to dominate the other solution ' $x 2$ ', if $\mathrm{i}$ ) $\mathrm{x} 1$ is no worse than $\mathrm{x} 2$ for all objectives and ii) $\mathrm{x} 1$ is strictly better than $\mathrm{x} 2$, at least for one objective. The algorithm also makes use of crowding distance strategy, which gives more importance to diverse solutions during ranking. From the ranked population, offspring designs are produced, using suitable parent selection (tournament selection) and mutation methods. The algorithm uses elitism principle such that elites of the population are given opportunity to be carried to the next generation. In this section only a summary of the algorithm is provided, for full details readers should refer to Deb et al.

Based on the fitness of the offspring and parents a new generation of population is created. As this process repeats the individuals in the population converge towards the desired objective. The NSGA-II algorithm uses crowding distance operator along with pareto dominance to rank different individuals in the population, forcing the individuals in successive generations to converge toward and spread out along the pareto front.

For offspring production, simulated binary cross over and polynomial mutation techniques are used. The offspring population is combined with the current generation population and selection is performed to set the individuals of next generation. Since all the previous and current best individuals are included in the population, elitism is ensured. The population is then sorted based on non-domination using rank and crowding distance. The NSGA-II based shape optimisation framework is developed in Matlab by adapting the work of Seshadri (2019).

\subsection{Shape optimisation using NSGA-II}

Generally, in a shape optimisation study, design variables would be geometric parameters such as length, width, leading edge radius etc. or simply $x, y$ coordinates of control points of a smooth curve. In general, the control points are joined by a Bspline curve to obtain a smooth 
shape. In this study, coordinates of control points are considered as design variables. The Ansys ICEMCFD package is used to generate the geometry using the in-built Bspline curve option. A CFD simulation is performed to evaluate the fitness value or objective function for each design. Meshing of the computational domain is carried out in ICEMCFD and the flow solution is obtained using the Fluent 17.2 commercial solver. After solving the given thermal problem in Fluent to the desired convergence level, the objective values are exported back to genetic algorithm as shown in the pseudo-code (Figure 1). Based on the objective values, designs are ranked and the algorithm continues with the offspring production for next generation. The loop continues till the specified number of generations are reached. Finally, for a multi-objective optimisation problem, the algorithm reports out the pareto of optimal designs.

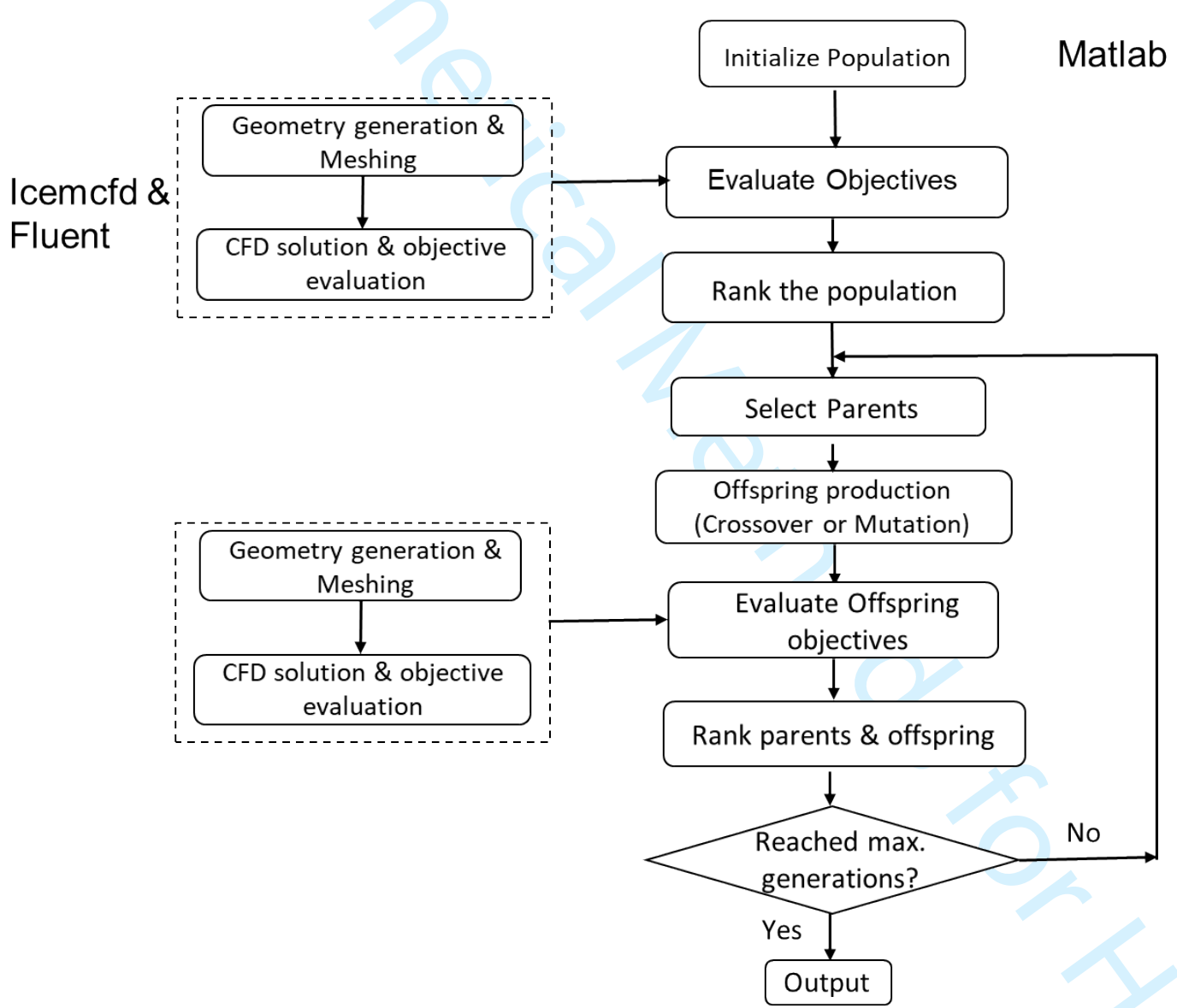

Figure 1 Genetic algorithm-based shape optimisation procedure 


\subsection{Validation}

The design framework is initially validated by replicating the study of Hilbert et al. (2006). In this forced convective problem (Figure 2), pressure drop minimisation and temperature change maximisation are considered as objectives. The computational domain and flow parameters and material properties are all detailed in the relevant publication, so it will not be duplicated here. However, the method used for geometry generation differs from the original study in that the geometry of the blade is generated with ICEMCFD Bspline curves. Only 2 control points are used for simplicity and for prevention of generation of negatively curved aerofoil shapes. The $\mathrm{x}, \mathrm{y}$ coordinates of the two points are considered as design variables. In total there are 12 design variables -4 for each blade (Table 1 ) details the design variables lower and upper bounds.

\begin{tabular}{|c|c|c|c|c|c|c|c|c|c|c|c|c|}
\hline & $\mathrm{X} 1$ & $\mathrm{Y} 1$ & $\mathrm{X} 2$ & $\mathrm{Y} 2$ & $\mathrm{X} 3$ & $\mathrm{Y} 3$ & $\mathrm{X} 4$ & $\mathrm{Y} 4$ & $\mathrm{X} 5$ & $\mathrm{Y} 5$ & $\mathrm{X} 6$ & $\mathrm{Y} 6$ \\
\hline $\begin{array}{l}\text { Min } \\
(\mathrm{m})\end{array}$ & 0.032 & 0.0025 & 0.0365 & 0.0025 & 0.042 & 0.0012 & 0.0465 & 0.0012 & 0.052 & 0.0025 & 0.0565 & 0.0025 \\
\hline $\begin{array}{l}\text { Max } \\
(\mathrm{m})\end{array}$ & 0.0345 & 0.0038 & 0.0385 & 0.0038 & 0.0445 & 0.0025 & 0.0485 & 0.0025 & 0.0545 & 0.0038 & 0.0585 & 0.0038 \\
\hline
\end{tabular}

Table 1 Lower and upper bounds for design variables

The optimisation is carried out for a population size of 30 and for 20 generations (same as Hilbert's). The computational domain and the obtained Pareto front are shown in Figure 3 and Figure 4 respectively. Very thin aerofoil like shapes with negative curvature near trailing edge, (which were obtained by Hilbert) are not obtained in this study as the minimum thickness of the shapes are hard limited by the bounds of the design variables given in Table 1. Heat bank shapes and their objective values are reasonably agreeing with Hilbert's results. The optimised shapes reported here are thicker than Hilbert's, due to the limits set for control points. 


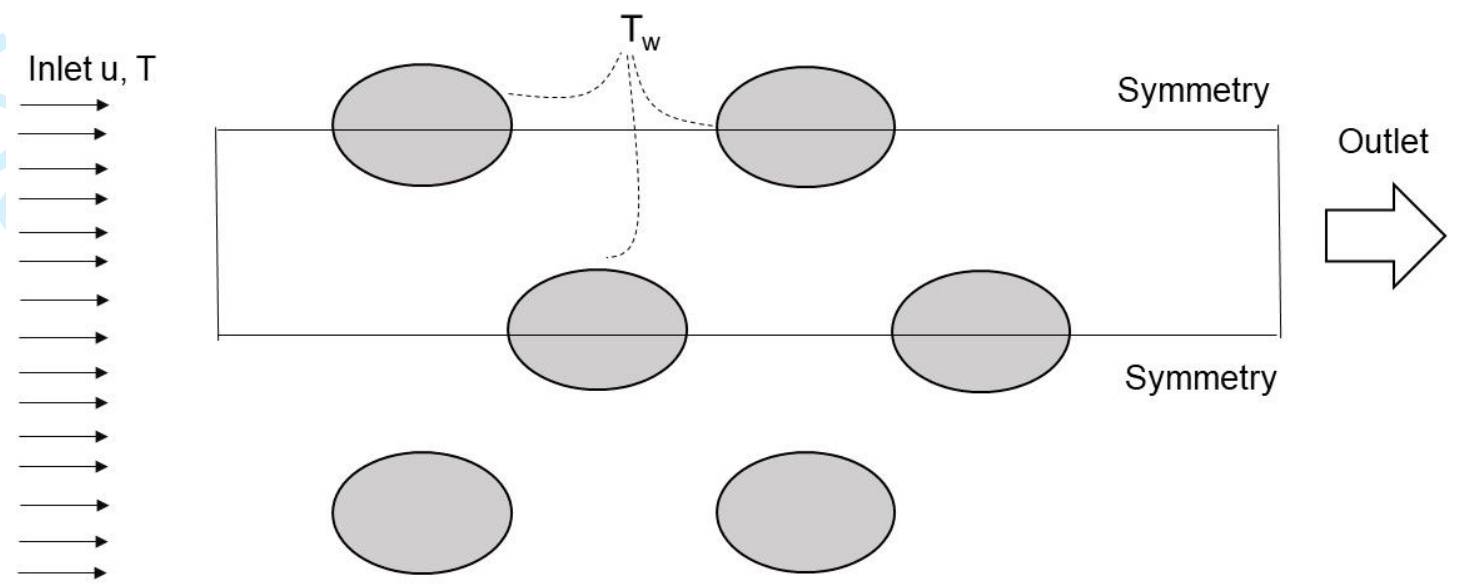

Figure 2 Tube bank heat exchanger cooled by cross flow

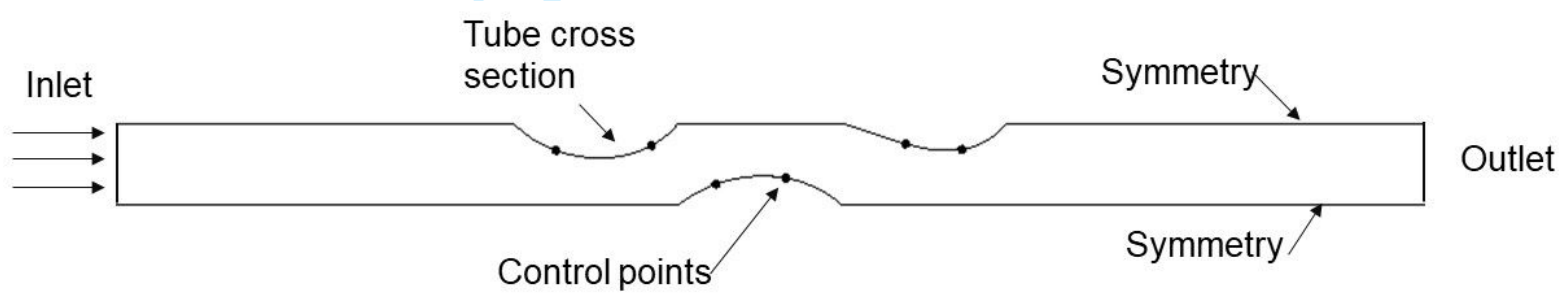

Figure 3 Computational domain used for heat exchanger cross section optimisation
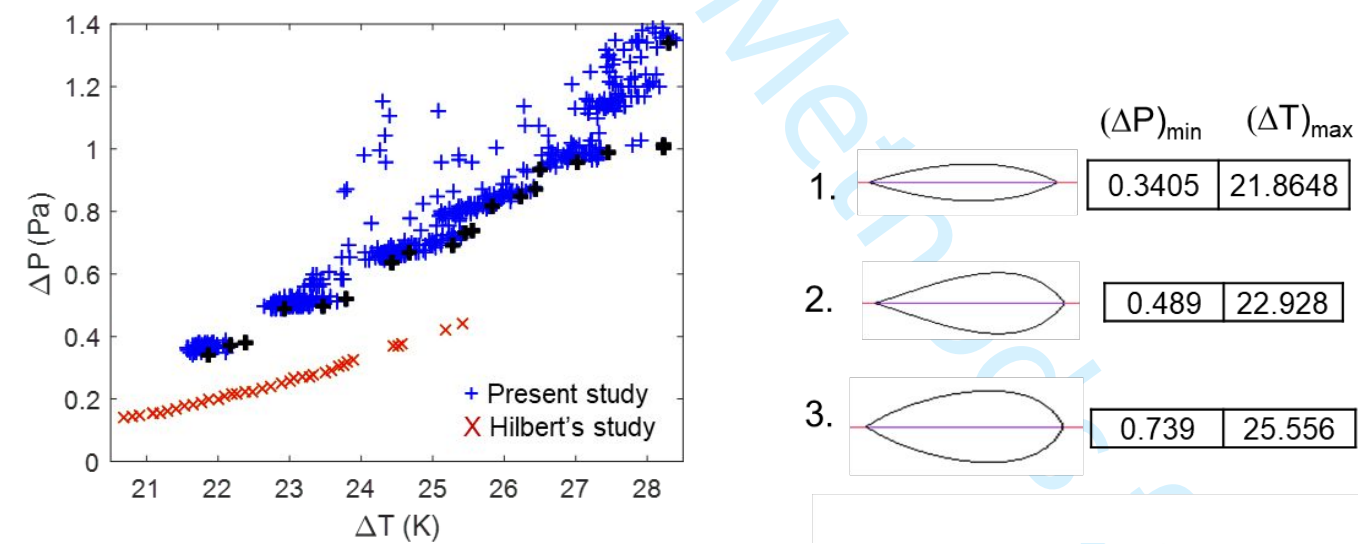

Figure 4 a) Results of all shape evaluations along with Pareto optimal front (Bold symbols), b) Selected optimised shapes and their objectives

\section{Shape optimisation of passively cooled heat sinks}

Heat exchangers are either cooled by active cooling or passive cooling methods. The later method is more cost effective, and most of the large industrial heat exchangers are of this type. The heat exchanger tubes are typically either circular or rectangular in shape. In this study, the NSGA-II based shape optimisation tool is used to find the optimum cross-sectional 
shape for the heat exchanger fins/tubes in a passive cooling setup.
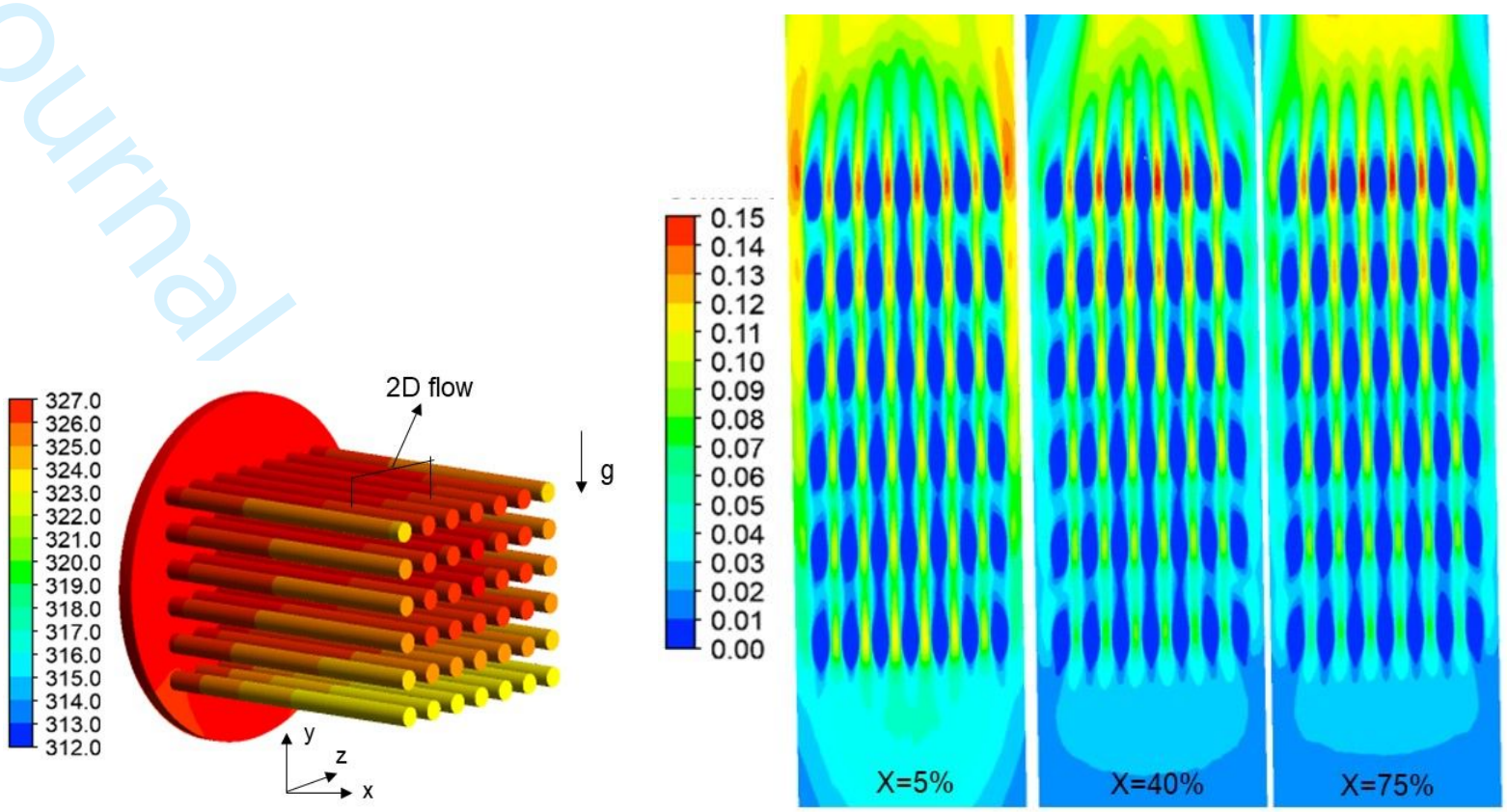

Figure 5 a)Temperature $(\mathrm{K})$ distribution and (b)velocity $(\mathrm{m} / \mathrm{s})$ field at different axial locations on a passively cooled pin fin heat sink

The fin length of horizontally mounted heat sinks are about 15 to 30 times higher than their fin diameter (D) or side-length. In a passively cooled heat sink, the thermal conductivity ratio between heat sink material and air, is typically higher than 10,000. Hence, the temperature variation within a pin fin, over its length will be fairly small on the top rows (Figure 5). Further, the laminar natural convective flow in the middle of the pin-fin will not be much affected by the base plate natural convection flow. So, it is reasonable to assume that the flow at the topmiddle region of pin-fins are two dimensional. Figure 5 shows that the velocity distribution are very similar at $40 \%$ and $75 \%$ of fin-length, indicating a two dimensional nature of flow. Hence, optimising the pin-fins cross-sectional shape is a reasonable exercise given that threedimensional shape optimisations are very expensive.

In this study fin cross sections of a typical passively cooled pin fin heat sink (Figure 5) are optimised. In a pin fin heat sink, bottom row fins experience different flow and temperature pattern than middle row fins. Hence optimisation of these fin's cross sections are dealt separately. To optimise bottom row fins, only two rows of fin arrangement is considered and to optimise middle row fins, three rows of fin arrangement is considered. 


\subsection{Optimisation of Bottom row fin's cross section}

To optimise bottom row fin's cross section, two rows of fin arrangement is considered (Figure 6) and in which the top row fins have a fixed circular cross section and bottom row fins have design control points. The two rows of fins are arranged in inline manner. The dimensions of computational domain are given in Table 2. Three control points are defined on the fin fixed at the symmetry plane and seven control points are defined on the outer fin. These control points are connected by ICEMCFD Bspline curves to obtain the heat sink shape. The $\mathrm{x}$ and $\mathrm{y}$ coordinates of control points are considered as design variables. The bounds of the $20, x$ and y design variables were carefully chosen to give more freedom for shape optimiser and also to avoid forming complex shapes which will fail during mesh generation (Table 3). The control point's (Figure $6 \mathrm{~b}$ ) limits ensure the formation of baseline circular to other random shapes during optimisation process. Additionally, the distance between fixed points ( $A, B$ \&C in Figure $6 b)$ to their immediate neighboring points is constrained to be greater than or equal to $0.00365 \mathrm{~m}$ to avoid formation of high negative curvature in the heat sink shape. The optimisation is carried out for three different inter-fin heights $(H)(H / D=0.42,0.83,1.67))$ and two different inter-fin widths (W) $(W / D=0.42,0.67)$ of heat sink arrangement.

The objectives of optimisation are maximisation of rise in temperature of the ambient air (between side inlet to top outlet of the domain) and minimisation of the total cross-sectional area of the heat sinks. The later objective will lead to less material for manufacturing and hence will result in cost reduction (ignoring the manufacturing cost). The heat sinks were maintained at an isothermal condition of $310 \mathrm{~K}$ and ambient air temperature is $288 \mathrm{~K}$. As the considered flow is laminar and steady, symmetry condition is exploited to model and solve only $1 / 2$ of the domain in order to save computation time. Other boundary conditions are shown in Figure 6.

\begin{tabular}{|c|l|}
\hline Parameter & \multicolumn{1}{|c|}{ Value } \\
\hline$D(m)$ & 0.012 \\
\hline$H / D$ & $0.42,0.83,1.67$ \\
\hline$W / D$ & $0.42,0.67$ \\
\hline$W_{D}(m)$ & $0.096,0.13$ \\
\hline
\end{tabular}




\begin{tabular}{|l|l|l|l|l|l|l|l|l|l|l|}
\hline & X6 & Y6 & X7 & Y7 & X8 & Y8 & X9 & Y9 & X10 & Y10 \\
\hline $\operatorname{Min}(\mathrm{m})$ & 0.0191 & 0.017 & 0.0166 & 0.0205 & 0.013 & 0.017 & 0.011 & 0.014 & 0.0125 & 0.0105 \\
\hline $\operatorname{Max}(\mathrm{m})$ & 0.0209 & 0.0194 & 0.0174 & 0.0214 & 0.0149 & 0.0194 & 0.013 & 0.016 & 0.0155 & 0.0132 \\
\hline
\end{tabular}

Table 3 Lower and upper bounds for the heat sink fin's design variables

The governing equations of this natural convection flow problem are given in Eqn $1-3$. The considered flow is laminar in nature as the Grashof number is 5800 based on the heat sink diameter (D). Body aligned quadrilateral meshes were created around the heat sinks and the total mesh size for this case is around 29000. Exact number of cell counts changes slightly with respect to the design iteration. A typical mesh structure around the heat sinks is given in Figure 7. To evaluate the mesh sensitivity, by halving the cell side length, a refined mesh of size, 79300 elements is created. The change in temperature rise objective (Eqn-4) due to the mesh refinement is found to be $2.4 \%$. As the change in objective is less and the increase in computational cost is more, it is decided to go ahead with 29000 element mesh.

Pressure based solver with semi-implicit method for pressure-linked equations (SIMPLE) method of pressure-velocity coupling is used to solve the governing equations. Pressure is solved using second order method while other primitive variables are solved using second order upwind method. Thermal conductivity and specific heat capacity of air are treated constant. The simulations were run, at least until continuity residue falls below 1e-3 (Figure 7).

$$
\begin{aligned}
& \nabla \cdot(\rho u)=0 \\
& \rho(u \cdot \nabla u)=\rho g \beta(T-T \infty)+\nabla \cdot\left\{\mu\left\{\nabla u+(\nabla u)^{T}\right\}\right\} \\
& \rho C_{p} u . \nabla T=k \nabla^{2} T
\end{aligned}
$$


The objectives for this shape optimisation problem are maximisation of air temperature rise (Eqn-4) and minimisation of heat sink cross sectional area (Eqn-5). The objectives (Eqn-6) are normalized for better convergence. The flow temperature is obtained by mass weighted averaging, with a higher temperature obviously correlating to increased heat exchanger performance. To maximise the temperature rise, the objective $\Delta \mathrm{T}$ is negated.

$$
\begin{gathered}
\Delta T=-\left(T_{\text {top }}-T_{\text {side }}\right) / 5 \\
\text { Area Ratio }=\frac{A_{\text {optimized }}}{A_{\text {circle }}}
\end{gathered}
$$

$\mathrm{A}_{\text {optimized:Total area of optimised heat sinks }}$

$\mathrm{A}_{\text {circle: }}$ Total area if all heat sinks were circular

Objective: Minimize $(-(\Delta T),($ Area Ratio $))$

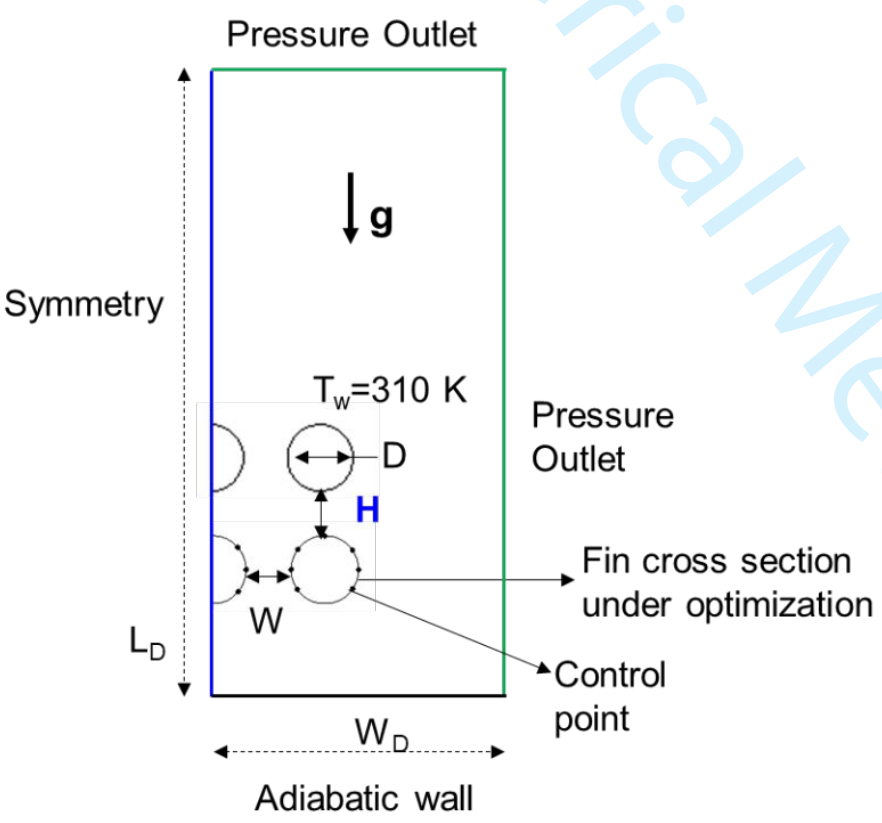

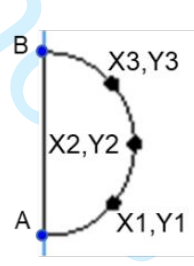

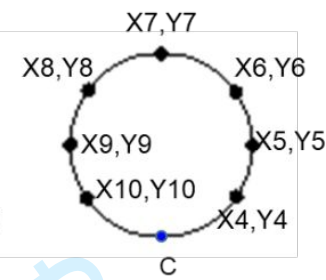

A,B,C : Fixed points

Figure 6 a) Computational domain used for the design of bottom row fin's cross section and (b) the design variables

\subsection{Optimisation of Middle row fin's cross-section}

The key aspect of this case is that the middle row fin's cross section is optimised considering the hot plume coming from the bottom row fins and its own plume interacting with the top 
row fins. The computational domain considered for this study is shown in Figure 8, with width $\left(W_{D}\right)$ of the domain is increased to $0.13 \mathrm{~m}$. The number of design variables remains the same and their minimum and maximum limits are also maintained the same. Optimisation is conducted for an inter-fin height value of $H / D=0.83$. The computational domain is discretised with 31800 elements in this case. The area objective is normalised by the total area of 3 circular fins (similar to bottom fin's case) and the temperature objective is normalised with $5 \mathrm{~K}$.
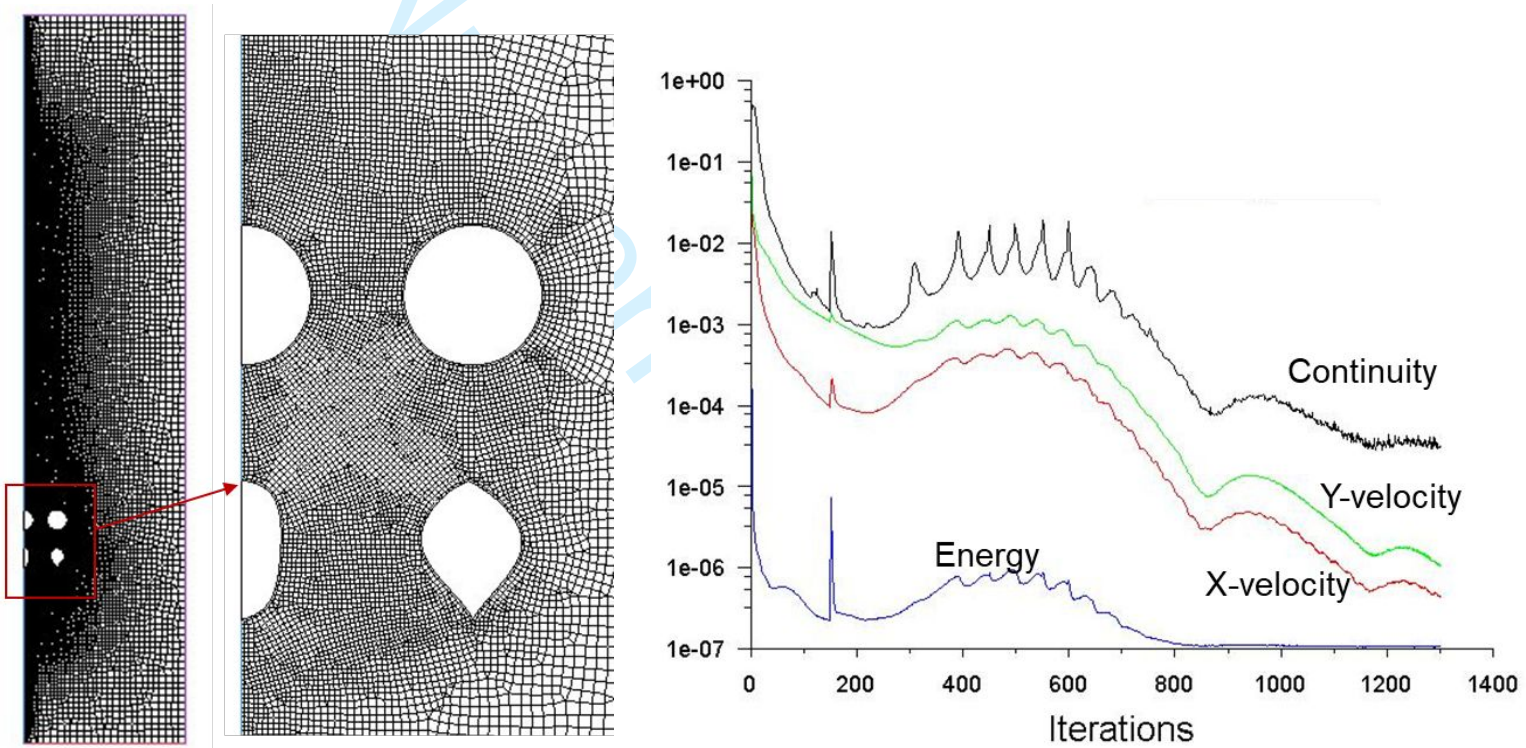

Figure 7 Typical mesh on the computational domain and a sample convergence history

\section{Results and Discussion}

The shape optimisation of heat sinks are conducted with a population size of 40 and a generation size of 40 . The initial population is selected by random seeding and this will have an effect on the final optimal designs obtained. Cross over is performed with $90 \%$ probability and mutation is performed with $10 \%$ probability. To minimise the effect due to random seed, 


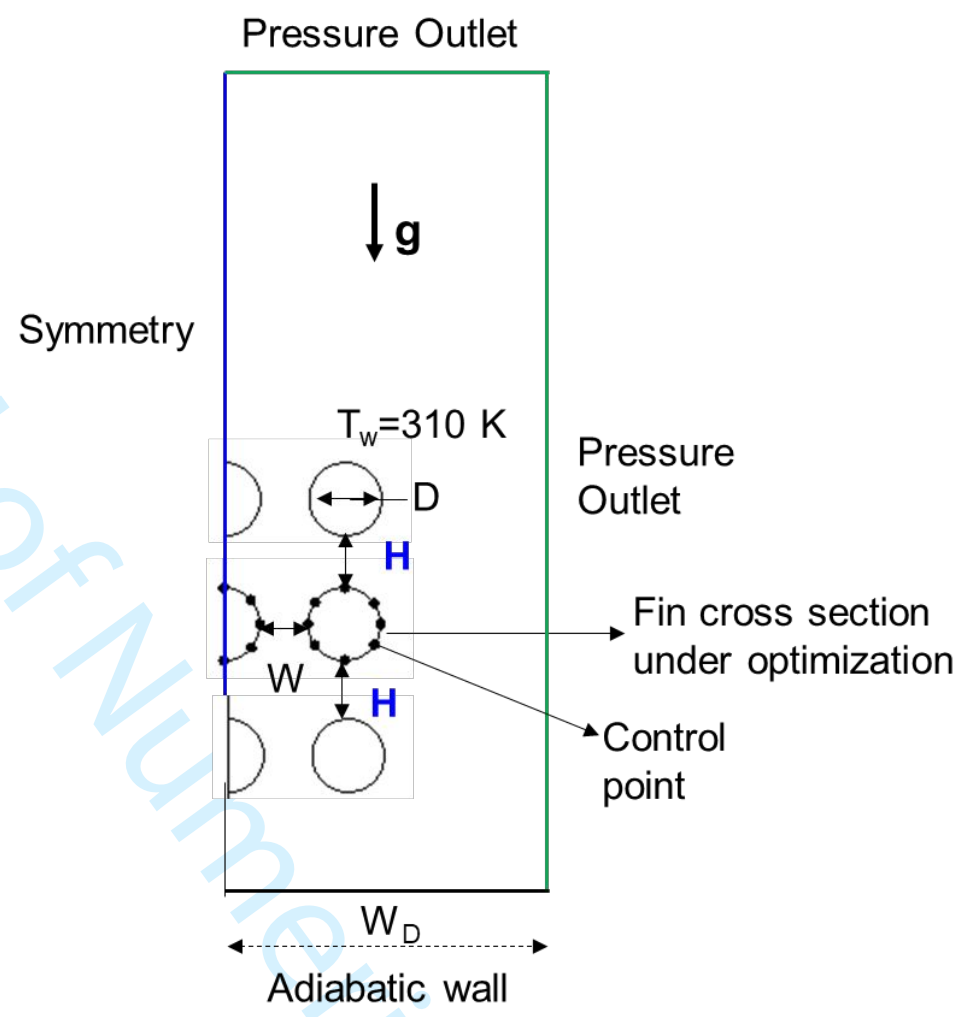

Figure 8 Computational domain used for the design of middle row fin's cross section

optimisation is repeated two times for each case and the best result is reported here. Total run time varies with respect to convergence of CFD runs and also with respect to initial random seed, but it is generally between 50 to 60 hours on 4 cores of 20 cores Intel Xeon workstation with 128GB RAM.

\subsection{Optimisation of Bottom row fin's cross section}

As the two objectives (Eqn-6) are conflicting with each other, this optimisation problem leads to a Pareto of optimal solutions. The Pareto front obtained for different inter fin heights (H/D) of $0.42,0.86,1.67$ are shown in Figure 9, Figure 10 and Figure 11 respectively. Results of all shape evaluations of 40 generations of $H / D=0.42$ case is shown along with its Pareto optimal front in Figure 9. Left hand side region of pareto front contains all feasible shapes tested during the optimisation, while the right-hand side indicates un-feasible region. The optimisation process defines notably different cross section designs for the different inter-fin heights indicating that the optimiser has accounted for the change in physics. When $H / D<=0.83$, the central fin is rectangular in shape for moderate area values. Further, when $H / D=0.42$, the centre fin's trailing edges $(T E)$ are rounded, because there is very little chance 
to diffuse or deflect the plume away from the top row heat sink. As H/D increases, the optimised central fins have pointed trailing edges to reduce the plume thickness and to decrease the interaction with the top row central fins.

The outer fins are asymmetrical, and are thicker on the inner side, creating a nozzle like constriction (along with central fin) to increase the free convection velocity (Figure 10). Along the flow direction, beyond maximum thickness location, some outer fins have convex curvature and some others have concave curvature. This plays a role in changing the convective flow direction and its velocity.

Generally, the outer fins have pointed trailing edges, but because of their asymmetric thickness and entrainment of ambient air around the trailing edges, the direction of plume is inclined inwards. The inward inclination of plume leads to weak interaction of plume with the top row fins and this enhances the heat transfer from the top-outer fins. The fins of maximum temperature rise ( $\Delta T \max )$ objective, deflect the flow inwards more effectively than the fins of minimum area-ratio (Amin) objective (Figure 12). Figure 12 also shows that velocity between the top and bottom row fins is higher for fins of $\Delta$ Tmax objective than for fins of Amin objective. As such, $H / D=1.67$ case will have enhanced heat transfer, due to higher inter fin distance. The optimised fins, by nozzle formation further increases the heat transfer (Figure 11).

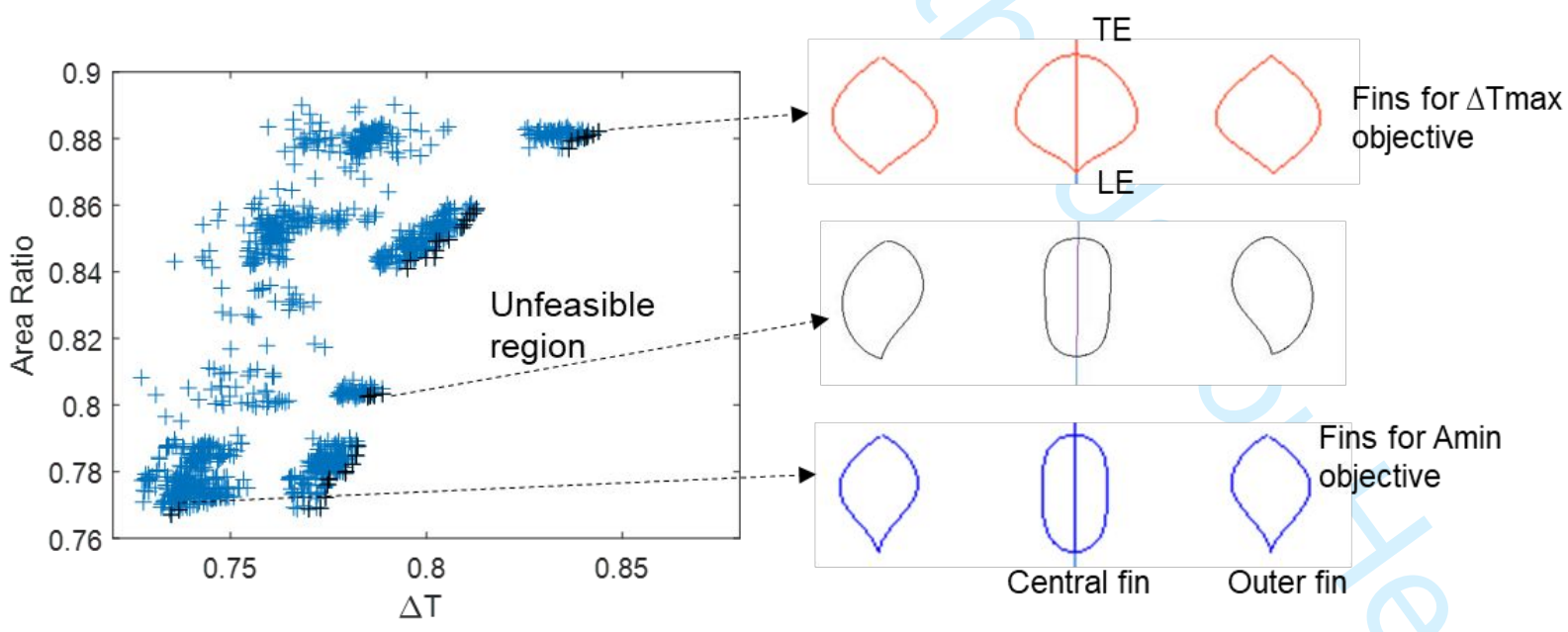

Figure 9 Results of all evaluations along with Pareto optimal front (Black + symbol) for bottom row fin shape optimisation ( $H / D=0.42)$ (LE: Leading edge, TE: Trailing edge) 


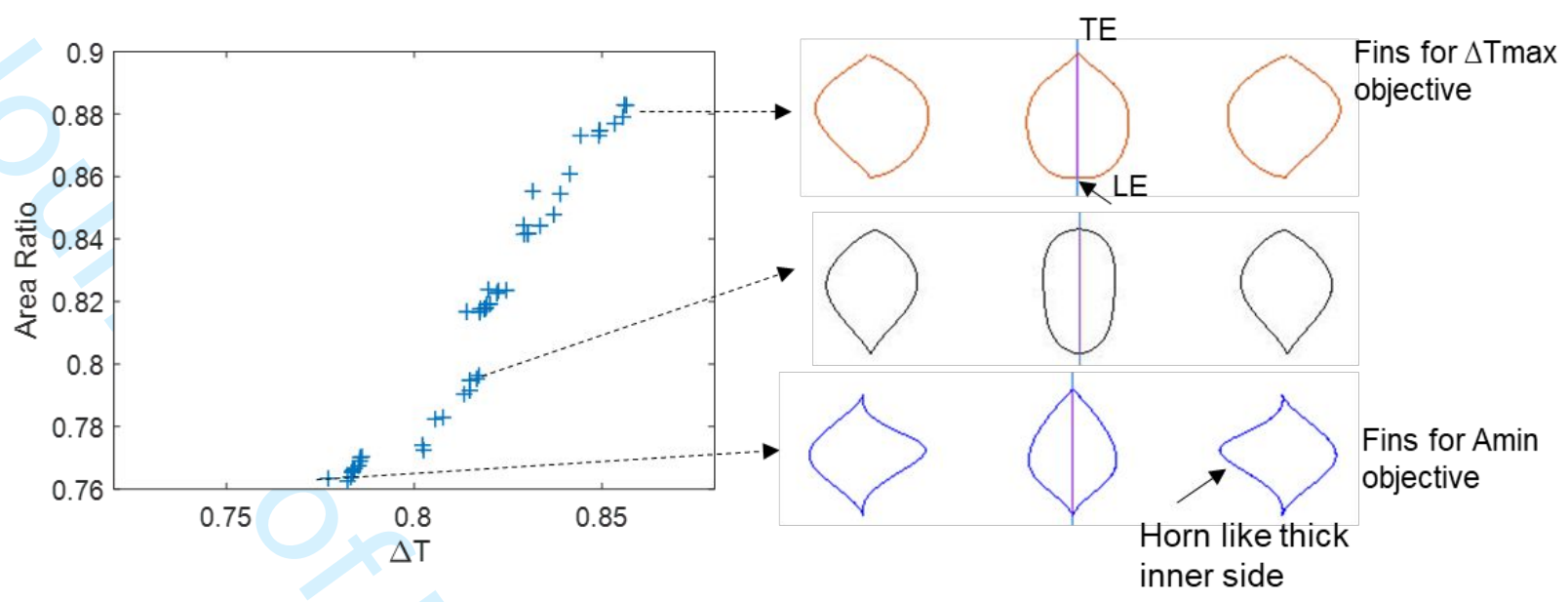

Figure 10 Pareto optimal front obtained for bottom row fin shape optimisation $(H / D=0.83)$

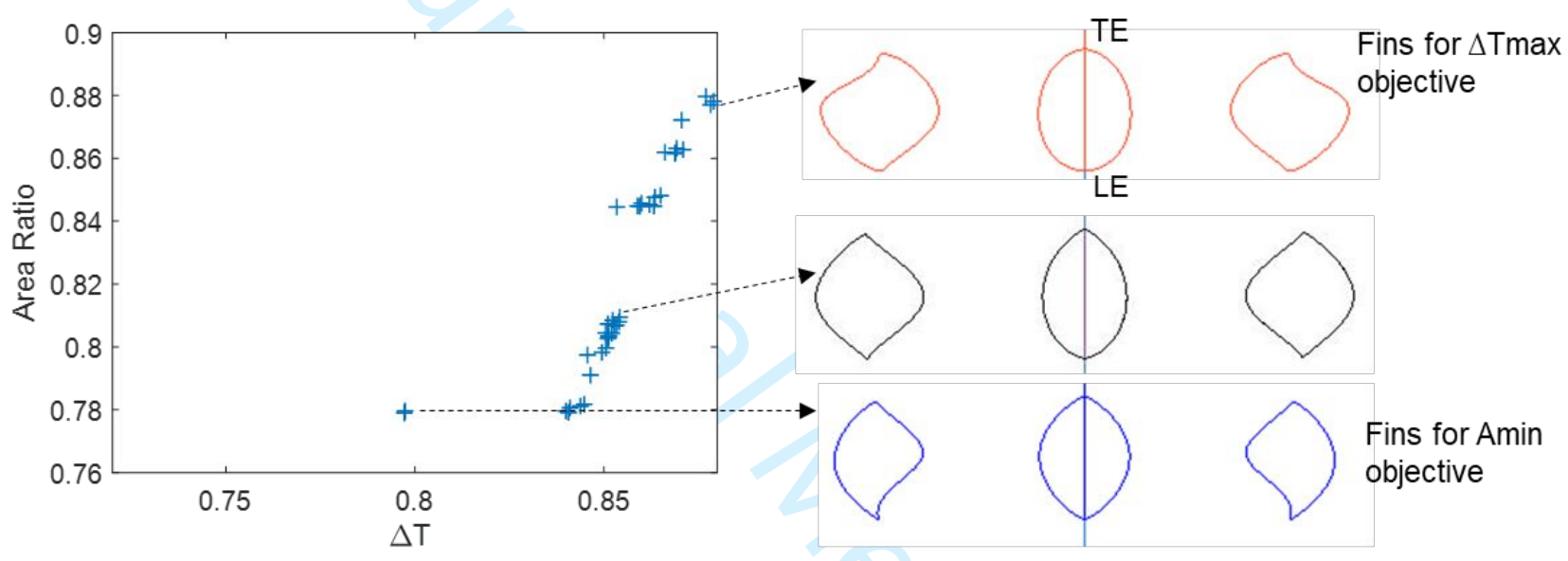

Figure 11 Pareto optimal front obtained for bottom row fin shape optimisation $(H / D=1.67)$

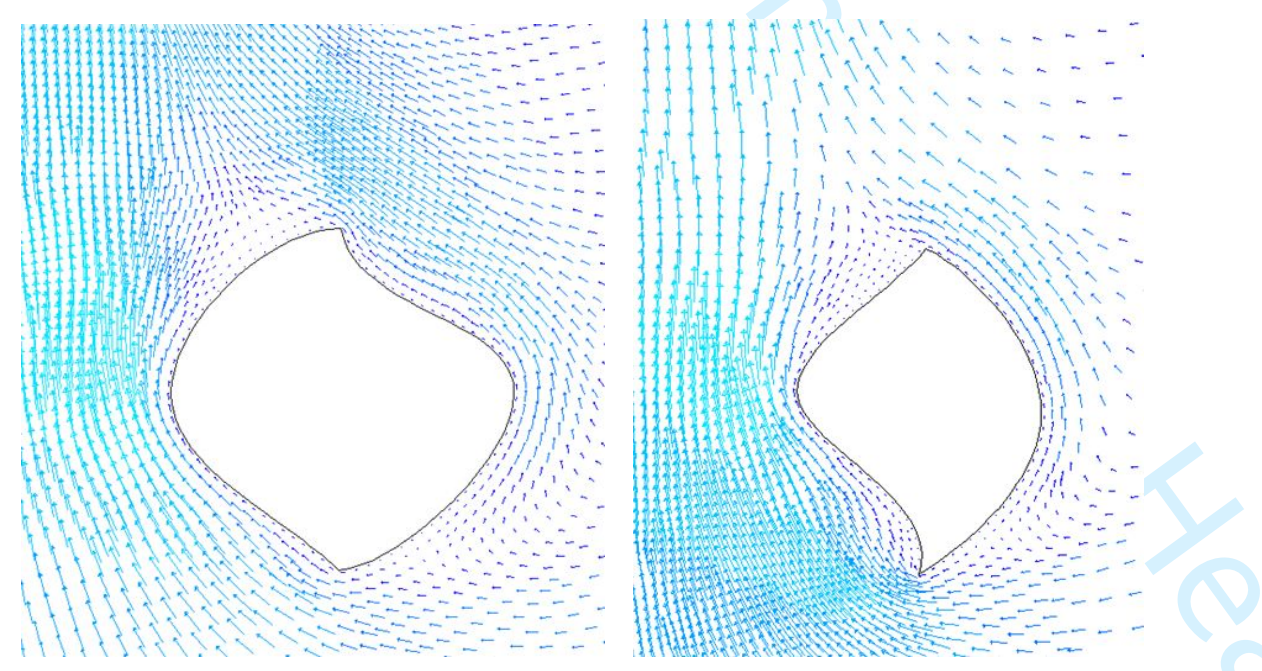

Figure 12 Velocity vector distribution around bottom row fins designed for $H / D=1.67$, a) $\Delta T \operatorname{Tmax}$ objective b) Amin objective 

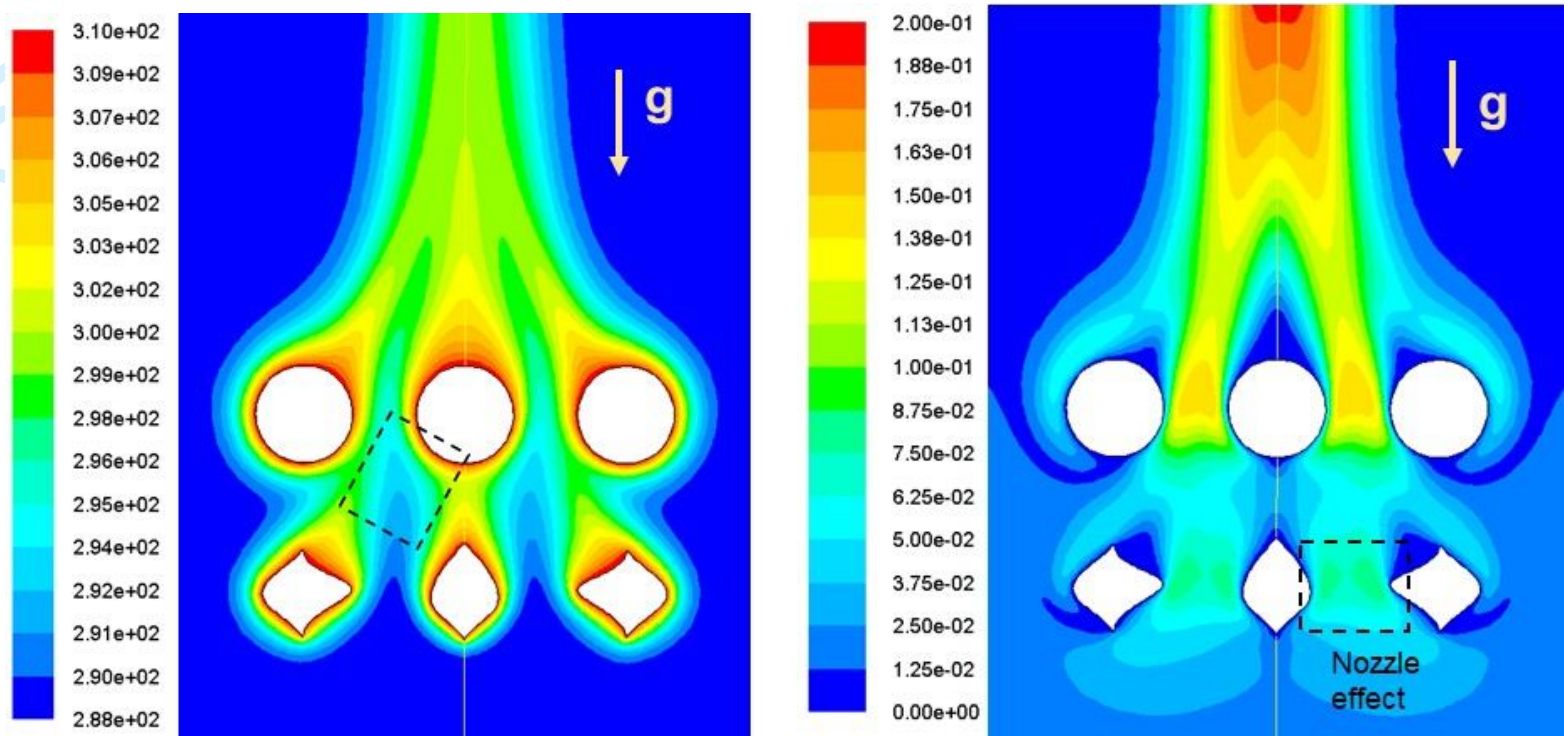

Figure 13 a) Temperature (K) contour and b) Velocity $(\mathrm{m} / \mathrm{s})$ contour over bottom row fins $(H / D=0.83)$ designed for Amin objective.

The increase in flow velocity due to horn like thick inner side of outer fin (nozzle effect) is clearly captured in Figure 13, which shows temperature and velocity field over $H / D=0.83$ Amin heat sink. The plume of the outer fin is deflected inwards and it is slightly diffused due to ingestion of cold air between top and bottom row heat sinks. This heat sink shape is much better than inclined rectangle with rounded edges, which are sometimes used in horizontally mounted LED heat sinks. The advantage of this optimized shape is that its outer-sides are lying aligned with the flow direction and the horn-like inner side deflect the cold flow towards central top fin, as this fin is exposed to more hot plume (Figure 13).

The objective values of these 3 cases are summarised in Table 4 for Amin and $\Delta$ Tmax objectives. Results show that, shapes obtained for $H / D=0.83$, Amin objective are the best as it gives higher $\Delta T$ for the similar value of heat sink Area. The random seed population selected for this study could have resulted in this better shape.

Optimisation of bottom row fins with reduced inter-fin distance:

In order to evaluate the effect of decreasing the inter-fin width on optimised shapes obtained, an optimisation is conducted for $W / D=0.42$ and $H / D=0.42$. The pareto front obtained along with few optimised shapes are shown in Figure 14. From the Table 4, which shows the objective values, it is clear that $\Delta T$ objective decreased with reduction in width. This is 
expected, as the hot plume from bottom row fins directly impinge on the top fins and the amount of cold air ingested in between central and outer fins would have decreased due to decreased width. Hence, the net heat transfer is less. The optimised shape, in general exhibits some similarity with earlier shapes. The fin in symmetry plane is similar to a rectangle with rounded edges. The outer fin (of Amin objective), forms a nozzle with central fin and also deflects the ingested flow inwards towards the top central fin.

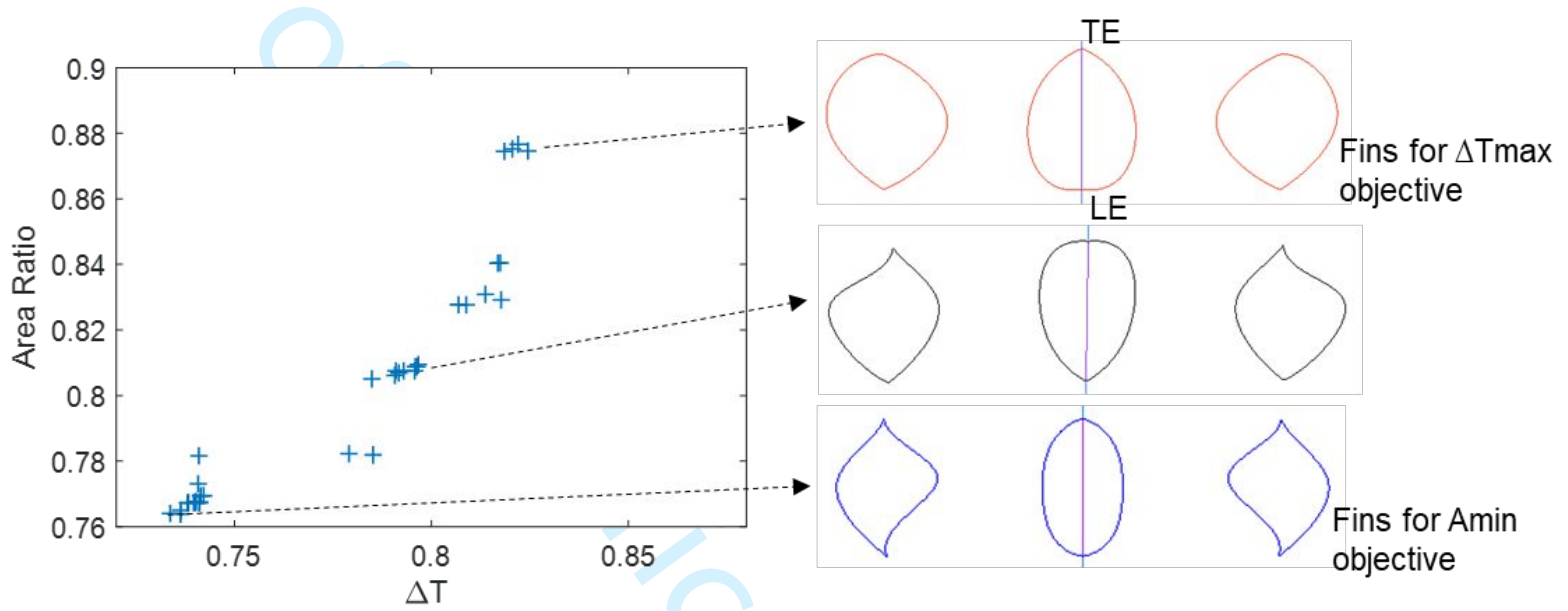

Figure 14 Pareto optimal front obtained for bottom row fin shape optimisation with $W / D=0.42$ and $H / D=0.42$

\begin{tabular}{|l|l|c|c|}
\hline & & Area Ratio & $\Delta T$ \\
\hline$H / D=0.42$ & $\Delta T_{\max }$ objective fin & 0.8821 & 0.8439 \\
\cline { 2 - 4 }$W / D=0.67$ & $A_{\min }$ objective fin & 0.7671 & 0.7349 \\
\hline$H / D=0.83$ & $\Delta T_{\max }$ objective fin & 0.8828 & 0.8565 \\
\cline { 2 - 4 }$W / D=0.67$ & $A_{\min }$ objective fin & 0.7626 & 0.7822 \\
\hline$H / D=1.67$ & $\Delta T_{\max }$ objective fin & 0.8781 & 0.8790 \\
\cline { 2 - 4 }$W / D=0.67$ & $A_{\min }$ objective fin & 0.7790 & 0.7973 \\
\hline \multirow{2}{*}{$\begin{array}{l}H \\
W\end{array} / D=0.42$} & $\Delta T_{\max }$ objective fin & 0.8746 & 0.8245 \\
\cline { 2 - 4 } & $A_{\min }$ objective fin & 0.7621 & 0.6979 \\
\hline
\end{tabular}

Table 4 Objective values corresponding to the extreme points of pareto front of bottom row fins optimisation

\subsection{Optimisation of Middle row fin's cross section}

The middle row fin's shape optimisation for $H / D=0.83$ and $W / D=0.67$ is conducted and the results are shown in Figure 15 and objective values are given in Table 5. The $\Delta T$ objective is again normalised with $5 \mathrm{~K}$ (similar to the two-row heat sink optimisation), but since a greater 
number of fins are modelled in the domain, the temperature rise of ambient air exceeds $5 \mathrm{~K}$ in some cases. This means that the $\Delta T$ objective can become greater than one. There is no pareto optimal solution with an 'Area Ratio' above 0.83. Examination of all the evaluated solutions showed that higher 'Area' designs were indeed tested but they were not dominant solutions, as the $\Delta T$ of those designs are much less than the reported Pareto optimal solutions. Since the optimised fins are in the middle row, thicker and bigger fins (beyond certain area value), may not be beneficial in achieving higher heat exchange in the three-row fin arrangement. Results show that, except for the Amin objective central fin, other shapes do not have a rounded or blunt LE/TE edges. The pointed TE avoids thicker plume leaving from the fin and pointed LE, prevents larger fin area getting affected by the impinging plume from the bottom fin. Outer fin with horn-like thick inner side, is found to perform well for this middle-row fin design scenario also (black colour, Figure 15).

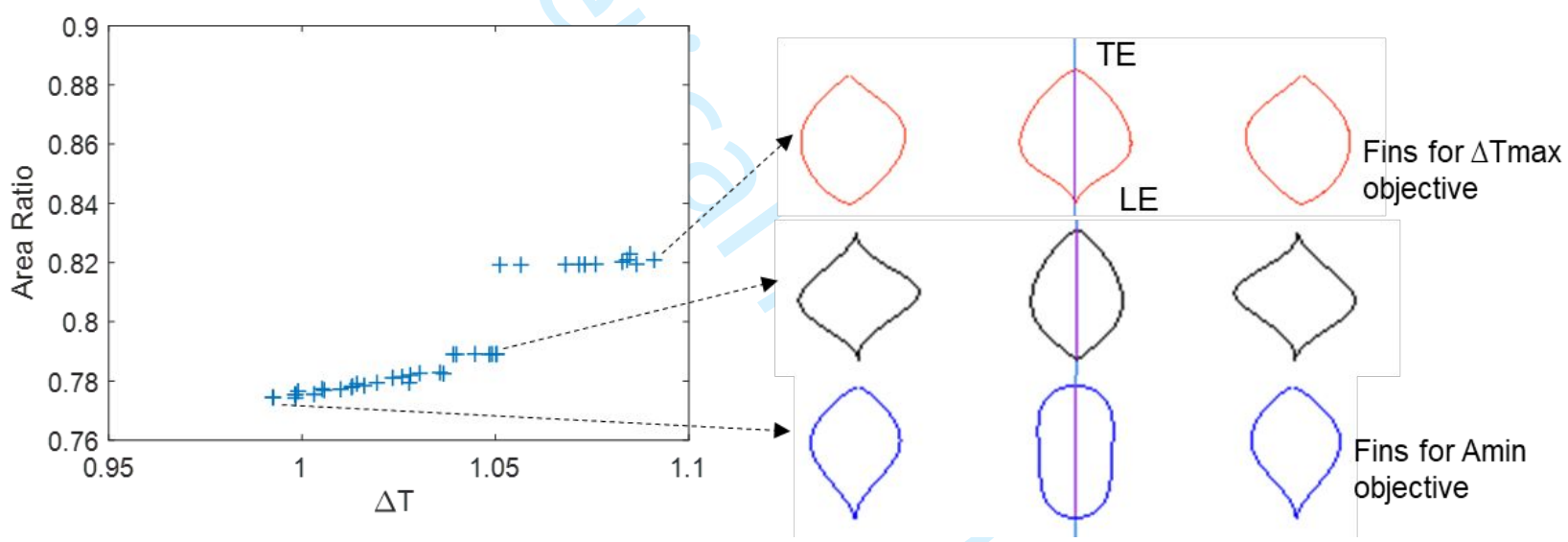

Figure 15 Pareto optimal front obtained for middle row fin shape optimisation

\begin{tabular}{|l|c|c|c|}
\hline & & Area Ratio & $\Delta T$ \\
\hline$H / D=0.83$ & $\Delta T_{\max }$ objective fin & 0.8208 & 1.0911 \\
\cline { 2 - 4 }$W / D=0.67$ & $A_{\min }$ objective fin & 0.7744 & 0.9924 \\
\hline
\end{tabular}

Table 5 Objective values corresponding to the extreme points of pareto front of middle row fins optimisation

\subsection{Comparison with conventional fin cross sections}

In order to verify and to quantify the performance improvement of the optimised fin cross section compared to circular (fin) shape, a 2D CFD simulation of two-row circular fins with a 
spacing of $H / D=0.42$ and $W / D=0.67$ has been carried out. The same meshing and convergence strategies used in the optimisation studies have been used for this validation analysis. The objectives are calculated based on the CFD results (Figure 16, Figure 17, Table 6). The $\Delta$ Tmax objective optimised fins, in spite having $12 \%$ less area, performs $5.4 \%$ better than the circular fins on the temperature rise objective. The optimised fins achieved this, by stimulating higher mass flow and by effectively convecting away the high temperature plume from the fins.
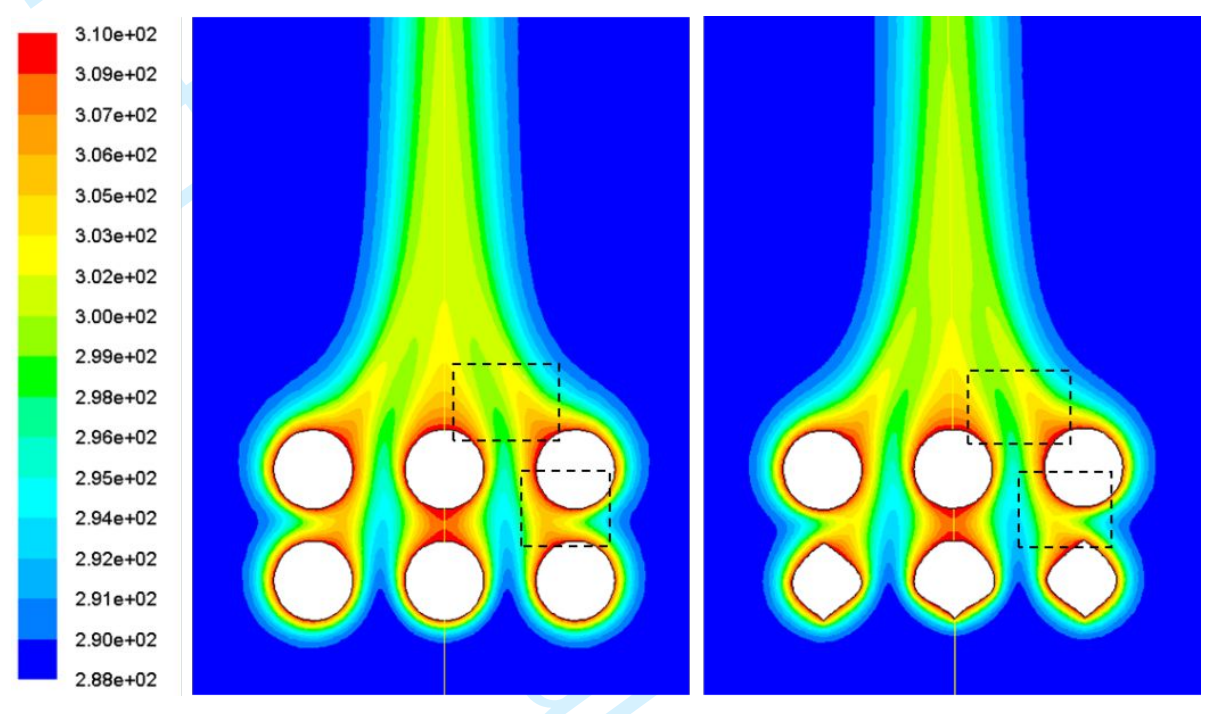

Figure 16 Temperature $(K)$ field comparison between circular fins and optimised ( $\Delta$ Tmax objective) bottom row fins
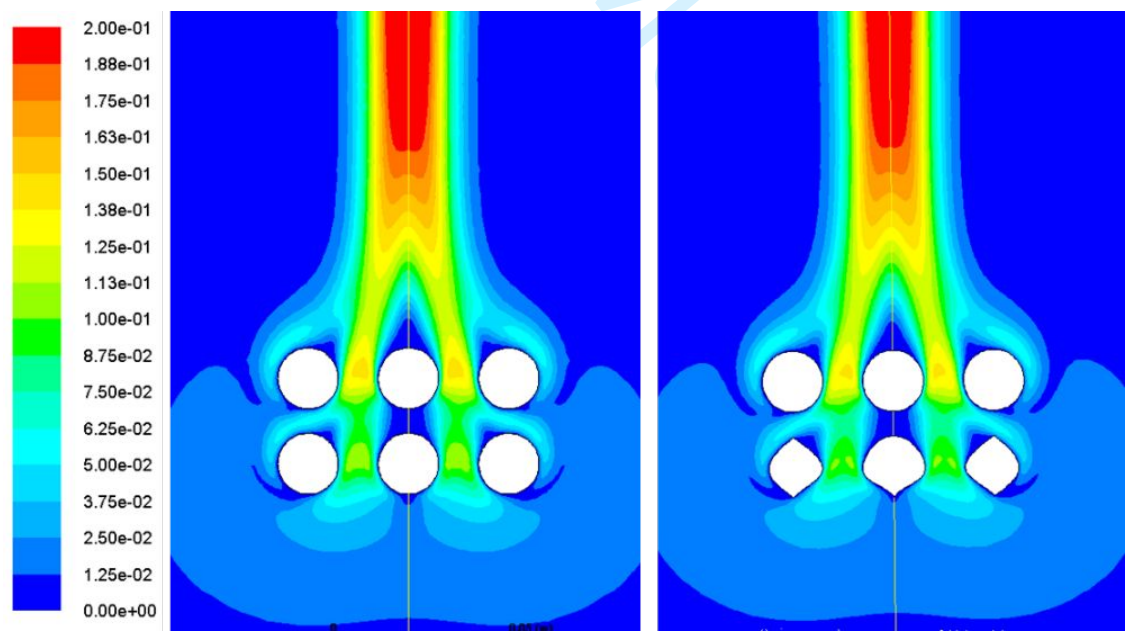

Figure 17 velocity $(\mathrm{m} / \mathrm{s})$ field comparison between circular fins and optimised ( $\Delta$ Tmax objective) bottom row fins

Further, the optimised shape is effective in ingesting the cold air flow for a longer distance into the heat sinks. Generally passive cooling will be more effective if the distance between 
the adjacent fins are increased or the interaction of their plumes is minimised. This technique also seemed to be employed to optimise the fin shapes. It can also be noted that Amin objective fins have $23.3 \%$ lower area and $8.2 \%$ lower cooling performance than circular fins.

\begin{tabular}{|c|c|c|c|}
\hline $\mathrm{H} / \mathrm{D}=0.42, \mathrm{H} / \mathrm{D}=0.67$ & Area Ratio & $\Delta \mathrm{T}$ & $\begin{array}{c}\text { Mass flow rate at } \\
\text { top side }(\mathrm{kg} / \mathrm{s})\end{array}$ \\
\hline $\begin{array}{c}\text { Optimised fins } \\
\left(\Delta \mathrm{T}_{\max } \text { objective }\right)\end{array}$ & 0.8821 & 0.8439 & 0.003269 \\
\hline $\begin{array}{c}\text { Optimised fins } \\
\left(\mathrm{A}_{\min } \text { objective }\right)\end{array}$ & 0.7671 & 0.7349 & 0.002931 \\
\hline Circular fins & 1.0066 & 0.8006 & 0.003145 \\
\hline
\end{tabular}

Table 6 Comparison of the objectives of circular fins along with the optimised fins

\subsection{Computational Validation}

In the present study, computational validation of optimised fin shapes are carried out by making use of the heat sink model described by Lazarov et al.(2018). Lazarov et al. conducted computational and experimental validation of their topology optimised heat sink designs against commercial heat sinks. Their heat sink consists of a circular disk of diameter $65 \mathrm{~mm}$ and thickness $3 \mathrm{~mm}$, on which pin-fins are attached at one end and a volumetric heat source with a base-plate is attached at the other end (Figure 18). Volumetric heat source (cube shaped) mimics a LED chip in the practical scenario. In the present study, the abovementioned heat sink design is retained but by modifying the pin-fin parts 3 different heat sinks are developed. A circular pin-fin heat sink with 42 fins, each fin with a diameter of $3.8 \mathrm{~mm}$ and $W / D=0.789$ and $H / D=0.84$ is designed and it is named as heat-sink $A$. The above inter-fin width and height values agree with the values used in the bottom row fin optimisation study (Section 4.1). As the optimisation study is carried out for inline fin arrangement, the 3D heat sink fins are also arranged in the inline manner.

To design the fins of optimised 3D heat sink, cross-sectional shape corresponding to Amin objective of $H / D=0.83$ (Figure 10) is utilised. The optimised 3D heat sink also has 42 fins with the same W/D and H/D values (Figure 18). Further, the major dimension (or characteristic length) of optimised fin cross section match with the diameter of the fin of the heat sink $A$. The total material volume of optimised 3D heat sink is $26.3 \%$ less than the circular pin-fin heat 
sink-A. To compare the performance of optimised heat sink with a heat sink of same volume, the third heat sink with circular pin-fins is designed (heat sink B). Each fin of heat sink B has a diameter of $2.79 \mathrm{~mm}$ and $H / D=0.84$ value is maintained to make a valid comparison. Aluminium is used as the heat sink material and Sika boom foam is used to insulate the volumetric heat source. The material properties are given in Table 7. Ambient air temperature is considered as $296.5 \mathrm{~K}$ coefficient of volumetric expansion of air is considered as $3.34 \mathrm{e}-3 \mathrm{1} / \mathrm{K}$.
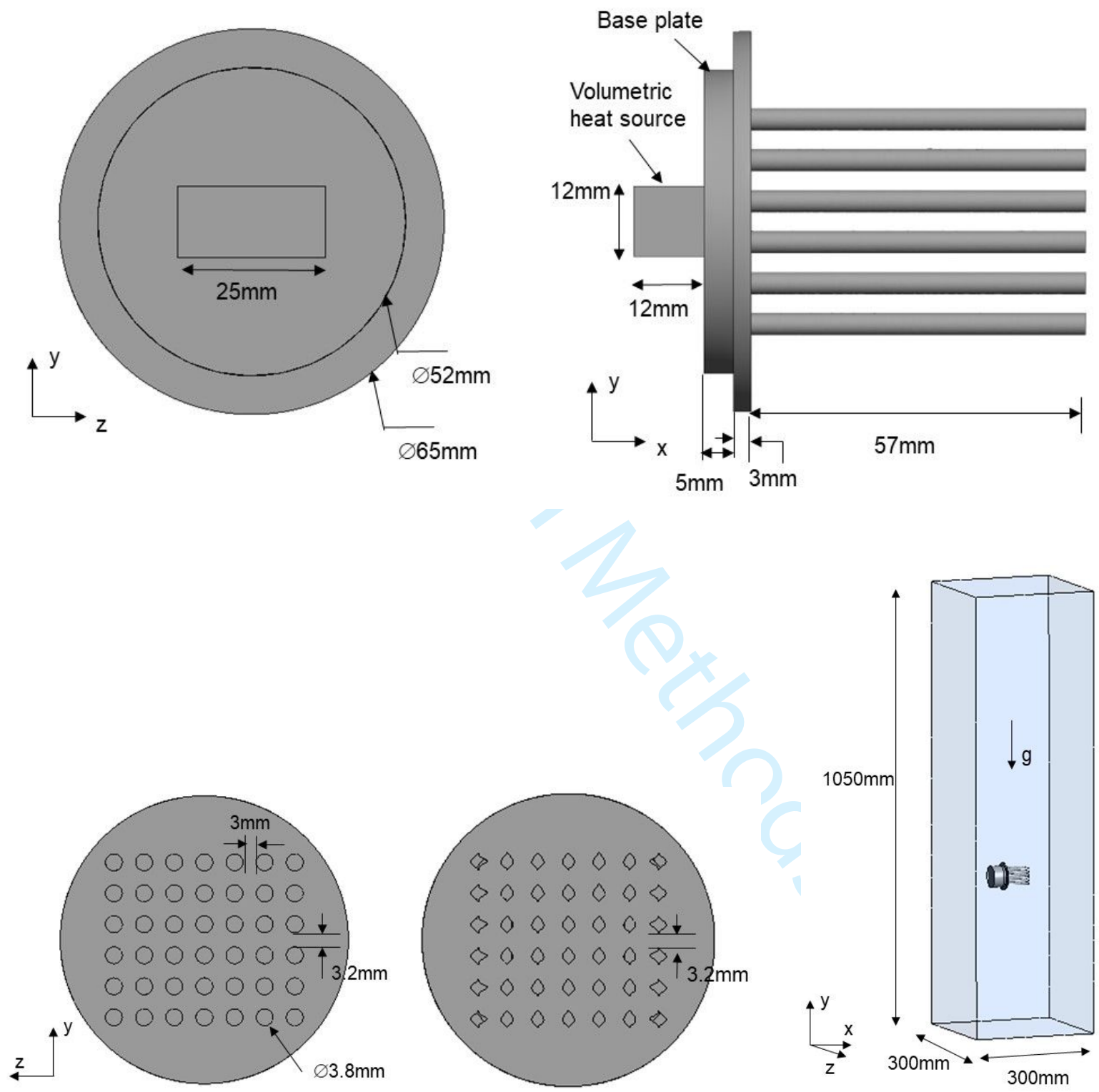

Figure 18 (a) Pin-fin heat sink ' $A$ ' and optimised heat sink geometric details, (b) Computational domain details 


\section{Results:}

\begin{tabular}{|l|l|l|l|}
\hline & $\mathrm{k}(\mathrm{W} / \mathrm{m} / \mathrm{K})$ & $\rho(\mathrm{kg} / \mathrm{m} 3)$ & $\mathrm{Cp}(\mathrm{J} / \mathrm{kg} / \mathrm{K})$ \\
\hline Air & 0.026 & 1.2 & 1003 \\
\hline Aluminium & 175 & 2702 & 903 \\
\hline Insulation & 0.026 & 1.2 & 1003 \\
\hline
\end{tabular}

Table 7 Heat sink material properties used in the validation simulation

The computational domain shape is shown in Figure 18b. The side and top sides are assigned pressure outlet boundary condition and bottom side is assigned adiabatic wall with no-slip boundary condition. The computational domain has 3 different material zones (Foam, Aluminium and air) and air zone is discretized with prism and tetrahedral cells while other zones are discretised with tetrahedral elements. For this conjugate heat transfer simulation, a mesh with 8.253 million elements is used. Same mesh setup is used for all the 3 heat sinks. Simulation is conducted for an input power $5.26 \mathrm{~W}$ in Fluent 18.2 solver. Simulation ran till the baseplate maximum temperature variation falls below $0.01 \mathrm{~K}$ over 100 iterations.

To assess the effectiveness of the three heat sinks, maximum temperature of the baseplate is evaluated. Lower baseplate temperature indicates higher heat sink's cooling effectiveness. $\Delta T_{B, \max }$ indicates the difference between maximum temperature in baseplate to ambient air temperature. Temperature distribution on different heat sinks (Figure 19) show that optimised fins are at lower temperature, indicating that these fins are effective in convecting the heat to the air. Temperature and velocity field values (Figure 20 \& Figure 21) at the middle of fin length show that optimised fins enable high flow velocity between the fin columns and that leads to effective convective cooling. The quantitative results (Table 8) show that, among the three heat sinks, optimised heat sink is more effective and its $\Delta \mathrm{T}_{\mathrm{B}, \max }$ is $10.3 \%$ lower than the heat sink $A$ and $1.6 \%$ lower than the heat sink $B$. This result validates that genetic algorithm based optimisers are capable of producing fin shapes which are better than the conventional circular fins. It must be noted that the cross sections optimised especially for bottom row fins is used to make all the fins (bottom, middle and top row fins) of the optimised heat sink. If fin cross sections are optimised for this particular pin-fin arrangement, a different and much 
better fin shape could be obtained which would have further higher cooling effectiveness. But this exercise will involve much higher number of design variables and hence computationally challenging.

\begin{tabular}{|c|c|c|c|}
\hline & $\begin{array}{c}\text { Circular } \\
\text { Heatsink A }\end{array}$ & $\begin{array}{c}\text { Optimised } \\
\text { Heat sink }\end{array}$ & $\begin{array}{c}\text { Circular } \\
\text { Heatsink B }\end{array}$ \\
\hline Volume $\left(1 \times 10^{-6} \mathrm{~m}^{3}\right)$ & 47.79 & 35.24 & 35.25 \\
\hline $\begin{array}{c}\text { Maximum } \\
\text { Temperature }(\mathrm{K})\end{array}$ & 327.92 & 324.67 & 325.27 \\
\hline$\Delta \mathrm{T}_{\mathrm{B}, \max }(\mathrm{K})$ & 31.42 & 28.17 & 28.77 \\
\hline
\end{tabular}

Table 8 Results of computational validation study

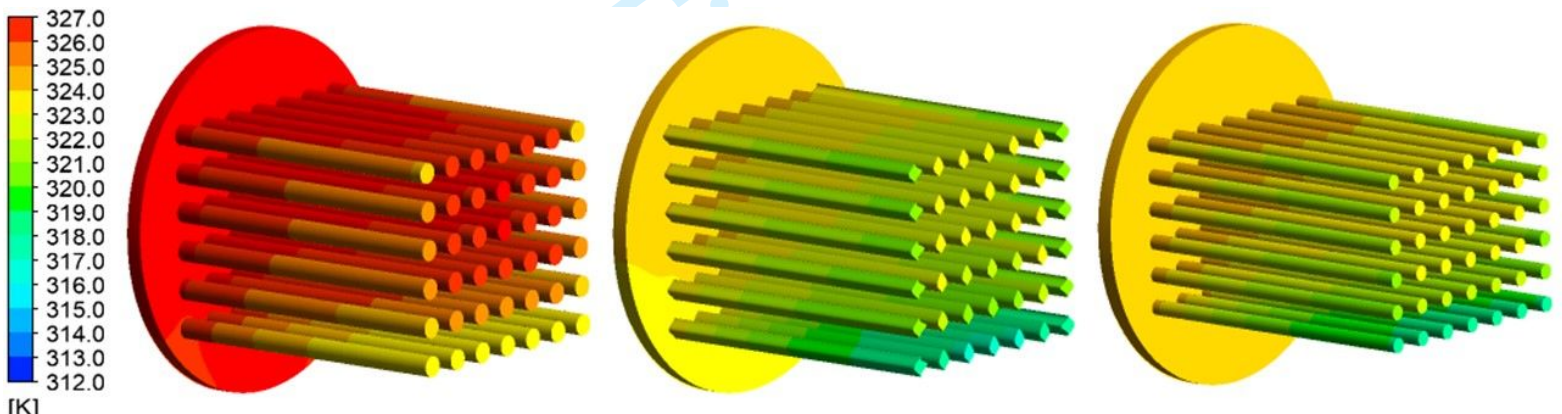

Figure 19 Temperature (K) distribution over heat sink surfaces. a) circular heat sink A, b) Optimised heat sink, c) Circular heat sink B

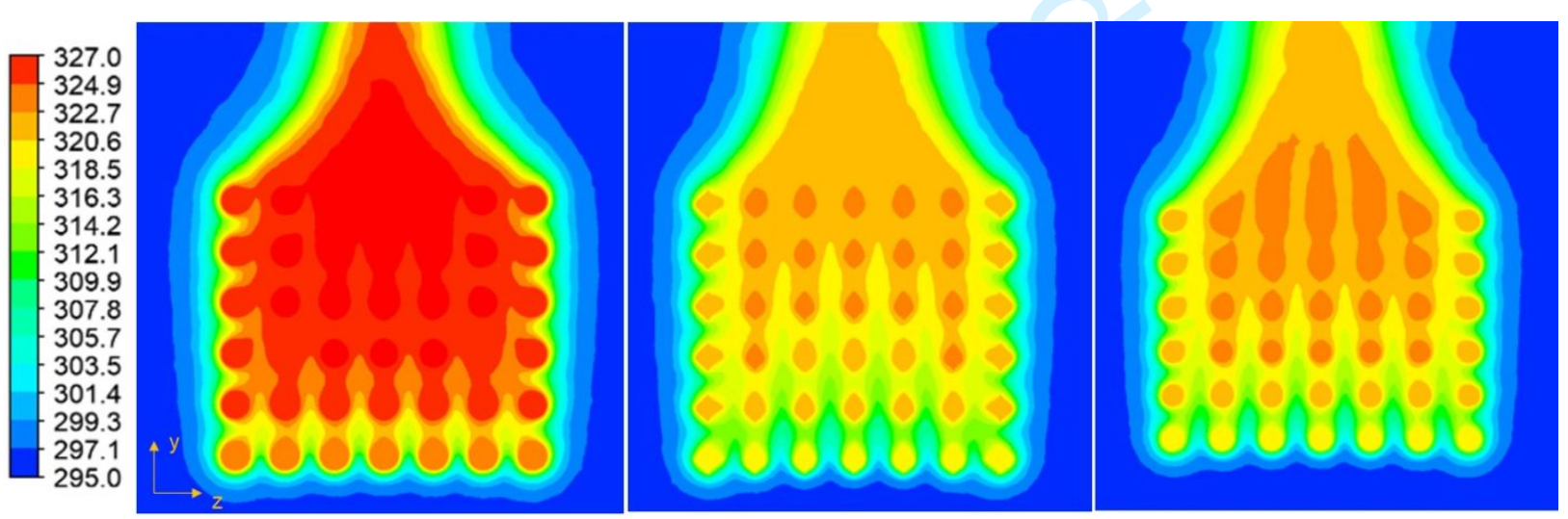

Figure 20 Temperature (K) field at mid-length of heat sink A, optimised heat sink, and heat sink B. 

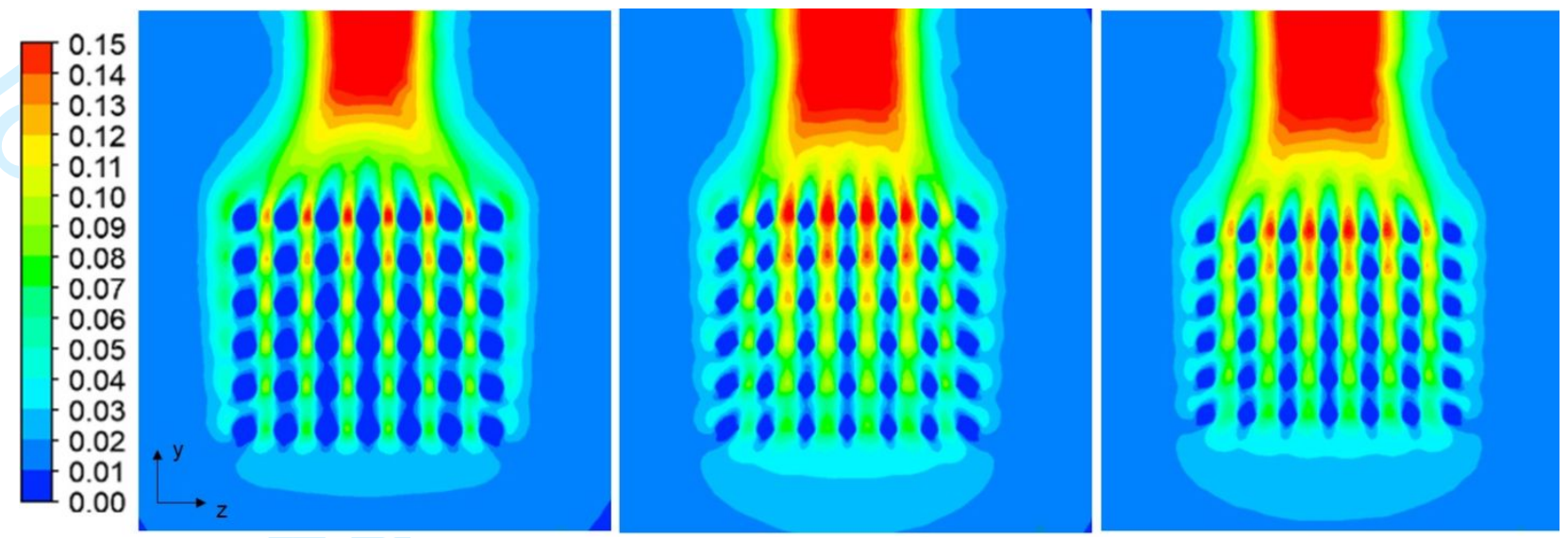

Figure 21 Velocity $(\mathrm{m} / \mathrm{s})$ field at mid-length of heat sink A, optimised heat sink, and heat sink B.

The optimised heat sinks can be manufactured by additive manufacturing technique, where the design is built by layer-by-layer deposition of molten material at required locations. Selective laser melting is one such popular method, wherein high-power density laser is used to melt metallic powders at select locations. Due to rapid advancement taking place in this field, cost per item of product manufactured by these techniques are continuously decreasing. Hence the cost of manufacturing these optimised fins will become acceptable in the near future.

\section{Conclusions}

This study focused on the assessment of the effectiveness of the NSGA-II genetic algorithm based multi-objective shape optimisation approach when applied to the design of crosssections of passively cooled heat sinks. The developed shape optimisation tool makes use of the CFD module and it was validated by repeating a previous work, with the shapes and objective values agreeing well with the earlier study. The validated framework was subsequently used to optimise the design of bottom row and middle row fins of passively cooled, horizontally mounted pin-fin heat sinks. The effect of inter-fin distance, on the optimised fin shape, is also studied. The multi-objective nature of the study obtained a pareto front that enabled trade-offs between the heat transfer performance and material usage to be explored.

Computational validation is performed by generating a 3D pin-fin heatsink by making use of the optimised fin cross sections and evaluating its performance by a CFD model. The 
performance of the optimised 3D heat sink is compared against circular pin fin heat sinks having same inter-fin distance. The results have shown that the optimised heat sink has $1.6 \%$ higher cooling effectiveness than the circular pin fin heat sink with same material volume and $10.3 \%$ higher cooling effectiveness than the circular pin fin heat sink with same characteristics fin dimension.

The ramifications of this study are that it is shown that the NSGA-II genetic algorithm based multi-objective shape optimisation approach can be effectively applied to the design of heat exchanger systems. The method can also be applied to systems where the level of performance needs to be retained while seeking a reduction in weight of the thermal management system or a combined improvement in performance: weight trade-off.

\section{Declaration of interest}

None

\section{References}

1. D.E. Goldberg, Genetic Algorithms in Search, Optimization, and Machine Learning, Addison-Wesley, Reading, MA, 1989.

2. K. Deb, A. Pratap, S. Agarwal, T. Meyarivan, A fast and elitist multi-objective genetic algorithm - NSGA-II, IEEE Trans. Evol. Comput. 6 (2002) 182-197.

3. M. C. Tayal, Y. Fu, and U.M.Diwekar, Optimal Design of Heat Exchangers: A Genetic Algorithm Framework, Ind. Eng. Chem. Res., 38,(1999) pp.456-467.

4. R. Hilbert, G. Janiga, R. Baron, D. Thévenin, Multi-objective shape optimization of a heat exchanger using parallel genetic algorithms, Int. J. Heat Mass Transfer 49 (2006) 2567-2577.

5. H. Peng, X. Ling, Optimal design approach for the plate-fin heat exchangers using neural networks cooperated with genetic algorithms, Applied Thermal Eng, 28 (2008) $642-650$

6. S. Sanaye, H. Hajabdollahi, Thermal-economic multi-objective optimization of plate fin 
heat exchanger using genetic algorithm, Applied Energy, 87 (2010), 1893-1902.

7. H. Hajabdollahi, M. Tahani, M. ShojaeeFard, CFD modeling and multi-objective optimization of compact heat exchanger using CAN method, Applied Thermal Eng.31 (2011) 2597-2604.

8. H. Najafi, B. Najafi, P. Hoseinpoori, Energy and cost optimization of a plate and fin heat exchanger using genetic algorithm, Applied Thermal Eng. 31 (2011) 1839-1847.

9. P. Ranut, G. Janiga, E. Nobile, D. Thevenin, Multi-objective shape optimization of a tube bundle in crossflow, Int. J. Heat and Mass Transfer 68 (2014) 585-598

10. A. Bar-Cohen, M. Iyengar, A.D. Kraus, Design of optimum plate-fin natural convective heat sinks, ASME journal of electronic packaging, 125 (2003).

11. R. Bahadur, A. Bar-Cohen, Thermal design and optimization of natural convection polymer pin fin heat sinks, IEEE transactions on components and packaging technologies, 28,2 (2005)

12. S.H. Yu, K.S. Lee, S.J. Yook, Optimum design of a radial heat sink under natural convection, Int. J. Heat Mass Transfer 54 (2011) 2499-2505.

13. D. Jang, S.-H. Yu, K.-S. Lee, Multidisciplinary optimization of a pin-fin radial heat sink for LED lighting applications, Int. J. Heat Mass Transfer 55 (4) (2012) 515-521, https://doi.org/10.1016/j.ijheatmasstransfer.2011.11.016.

14. D. Jang, S.-J. Yook, K.-S. Lee, Optimum design of a radial heat sink with a fin height profile for high-power LED lighting applications, Applied Energy 116 (2014) 260-268, https://doi.org/10.1016/j.apenergy.2013.11.063.

15. Y. Joo, S. Kim, Comparison of thermal performance between plate-fin and pin-fin heat sinks in natural convection, Int. J. of Heat and Mass transfer 83 (2015), 345-356.

16. M. Imran, N.A.Pambudi, M.Farooq, Thermal and hydraulic optimization of plate heat exchanger using multi-objective genetic algorithm, Case studies in thermal engineering, 10 (2017), 570-578

17. D. Copiello, G. Fabbri, Multi-objective genetic optimization of the heat transfer from longitudinal wavy fins, International J. of Heat and Mass transfer, 52 (2009), 11671176.

18. H. Azarkish, S.M.H. Sarvari, A. Behzadmehr, Optimum design of a longitudinal fin array with convection and radiation heat transfer using a genetic algorithm, International J. of thermal sciences, 49 (2010) 2222-2229. 
19. R. Venkata Rao, A. Saroj, P. Oclon, J. Taler, Design optimization of heat exchangers with advanced optimization techniques: A review, Archives of computational methods in engineering, vol. 27, pp.517-548, 2020.

20. J. Alexandersen, O. Sigmund, N. Aage, Large scale three-dimensional topology optimisation of heat sinks cooled by natural convection, Int. J. Heat Mass Transfer, 100 (2016) 876-891, https://doi.org/10.1016/j.ijheatmasstransfer.2016.05.013.

21. J. Alexandersen, O. Sigmund, K.E. Meyer, B.S. Lazarov, Design of passive coolers for light-emitting diode lamps using topology optimisation, Int.J.Heat and Mass Transfer, 122 (2018), 138-149

22. E. M. Dede, S.N. Joshi, F. Zhou, Topology optimization, additive layer manufacturing and experimental testing of an air-cooled heat sink, J. of Mechanical design, 137, (11), 2015.

23. M. Santhanakrishnan, T.Tilford, C.Bailey, Performance assessment of density and level-set topology optimisation methods for three dimensional heat sink design, J. of Algorithms \& Computational Technology, vol.12 (3),2018, 273-287.

24. M. Santhanakrishnan, T.Tilford, C. Bailey, Multi-material heat sink design using levelset topology optimization, IEEE Transactions on components packaging and manufacturing technology, 9 (8), 2019.

25. T. Dbouk, A review about the engineering design of optimal heat transfer systems using topology optimization, Appl. Thermal Eng., vol. 112, pp. 841-854, Feb. 2017

26. A. Seshadri (2019). NSGA - II: A multi-objective optimization algorithm (https://www.mathworks.com/matlabcentral/fileexchange/10429-nsga-ii-a-multiobjective-optimization-algorithm), MATLAB Central File Exchange. Retrieved December $12^{\text {th }}, 2019$.

27. B. Lazarov, O.Sigmund, K.E.Meyer, J.Alexandersen, Experimental validation of additively manufactured optimized shapes for passive cooling, Applied Energy, 226 (2018) 330-339 